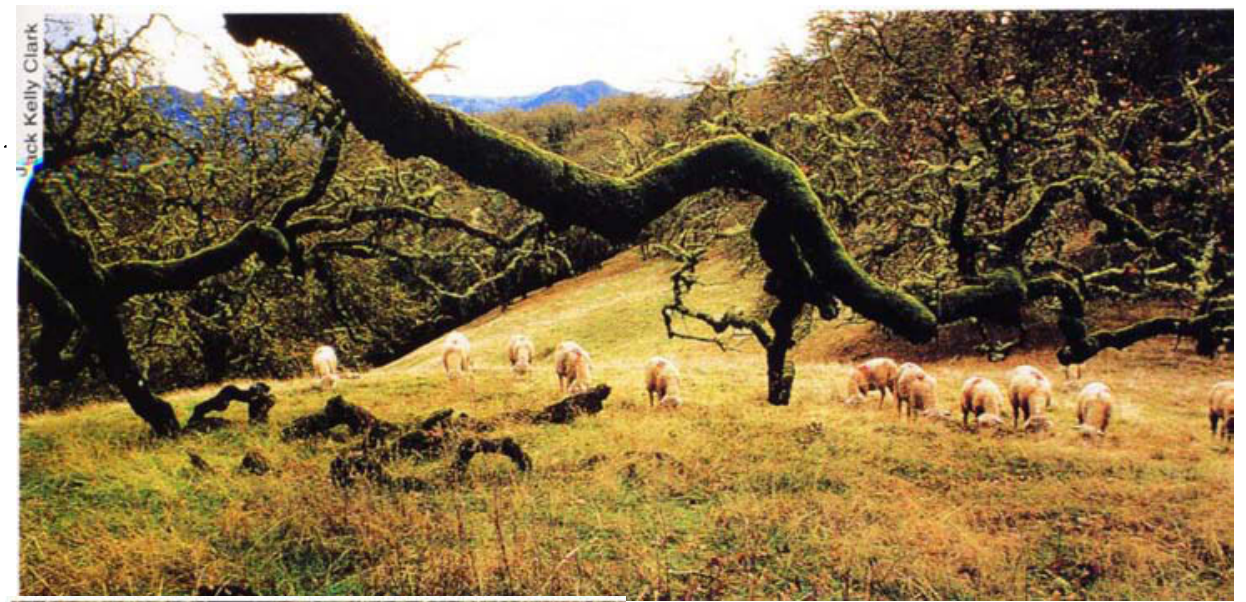

Sheep research at the UC Hopland Research and Extension Center has focused on breeding to improve performance, and on the sexual behavior of rams. Sheep graze on a pasture at the center in southern Mendocino County.
Scientists working at the UC Hopland Research and Extension Center (HREC) have made important contributions to the sheep industry in breeding and genetics, and in the understanding of animal behavior. A long-term experiment involving HREC was initiated in 1960 to evaluate the effects of selection environment on sheep performance under range conditions. Selection of the UC Davis flock, representing the favorable conditions typical of purebred flocks where most breeding rams are raised, resulted in more within-flock improvement in weaning weight than selection under range conditions at Hopland. However, when the UC Davis- and Hopland-selected lines were compared under range conditions at HREC, the two were equal in weaning weight, and the Hopland line was superior in reproduction and total productivity. We concluded that selection should take place in the environment of use. In the late 1970 s, investigations were initiated to develop cost-efficient techniques for fostering lambs to unrelated ewes; an effective new method was developed using stockinette jackets and neatsfoot oil to transfer odors. Likewise, research on sexual behavior has resulted in several relatively simple behavioral tests that can be used to determine the performance of rams.

\title{
Sheep research offers alternatives to improve production
}

\author{
Edward O. Price \ G. Eric Bradford
}

he goal of the sheep research pro-
gram at the UC Hopland Research and Extension Center (HREC) has been to develop more productive strains of sheep for the North Coast region of California. Scientists have made important contributions to the sheep industry in breeding and genetics, and in the understanding of animal behavior. The objectives of the breeding and genetics research have been to increase the number of lambs born per ewe and lamb survival, and to enhance weaning weights. The behavioral research has focused on improving the reproductive efficiency of sheep by developing improved fostering (grafting) techniques for ewes and by studying the development and expression of sexual behavior in rams.

\section{Breeding and genetics}

The genetic makeup of livestock sets the upper limit for their performance, making it an important factor in determining the productivity of any livestock enterprise. There is much genetic variation between and within breeds in all livestock species. Research at HREC has helped to elucidate some of the ways in which this variation can be used to improve sheep productivity.

The first requirement for livestock production is that the animals are well adapted to the production environment, including climate, nutrition and management. The choice of an appropriate breed or cross is usually the first key step in ensuring adaptability, for which the best indicators are efficient reproduction and low mortality. How ever, long-term selection strategies to improve the population can also affect traits such as growth rate and wool production.

Lamb production has been the primary focus of breeding and genetics research at HREC. Historically an important sheep-producing region, the North Coast was originally noted for wool production. By the time HREC was established in 1951, the sale of lambs provided the majority of the region's sheep income. Research in the 1950 s and 1960 s was designed to compare the productivity of various breeds and crosses under annual grassland conditions of the area.

In one study from the 1950 s, crossbred ewes born to Merino ewes and sired by Columbia or Corriedale rams 


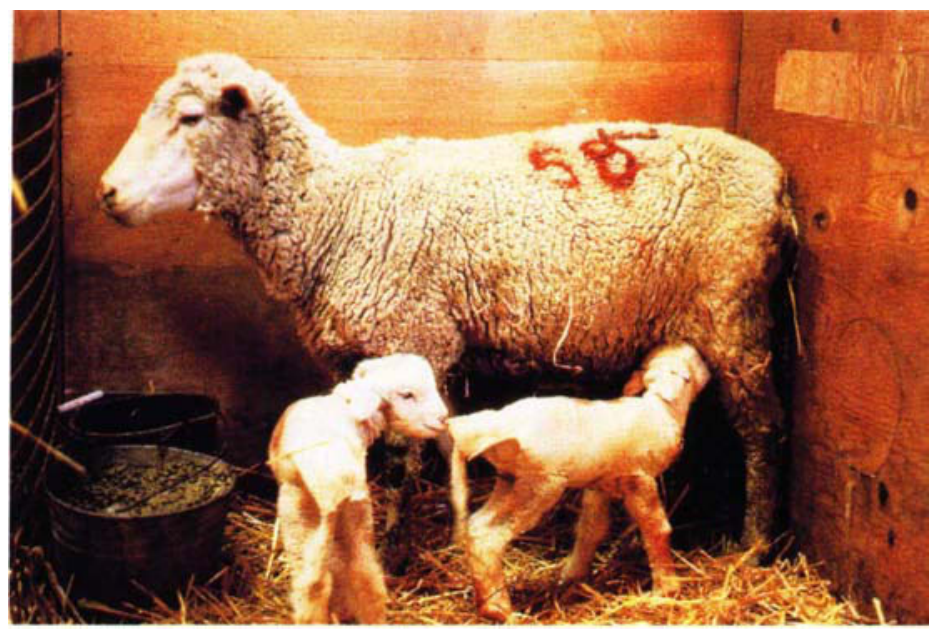

A ewe that has given birth to a single lamb adopts a second alien lamb using the odor-transfer technique, in which cloth stockinette jackets are fitted onto lambs at birth and then exchanged at the time of fostering.

were found to be superior to ewes sired by Border Leicester or Romeldale rams (W.C. Weir and D.T. Torell, unpublished data).

A 2-year study of the growth and finishing ability of market lambs demonstrated the advantages of Suffolk rams as sires of crossbred market lambs to increase lamb weaning weights (Bradford et al. 1960). However, because the North Coast counties were predominantly producing feeder lambs at the time, and only $25 \%$ to $35 \%$ were large and fat enough to go directly to slaughter at weaning, an experiment was conducted to compare Suffolk and Southdown sires and determine if the latter would sire lambs with higher fat percentages at weaning. The Southdown crosses had a higher percentage of lambs with slaughter finish and a greater survival rate, but the faster growth rates of the Suffolk-cross lambs more than compensated for the advantages of the Southdown crosses. Dorset rams also sired more fat lambs than Suffolks, but the lighter weights of the Dorset crosses resulted in no difference in net returns.
In another study, Suffolk $x$ Hampshire crossbred rams were superior to those from either parent breed, in terms of survival and carcass grade of their lambs, and in uniformity of the lambs for all traits measured (Bradford et al. 1963).

It is a common practice for range livestock producers raising cattle or sheep to purchase breeding males from purebred operations in which the feeding and management levels are more favorable than those that their offspring will experience. This is done for several reasons, but nonetheless it has not been clear that the practice improves performance of the range herd or flock as much as selection under range conditions. The range environment usually involves inadequate nutrition for at least part of each year, more exposure to harsh weather and less intensive management.

\section{Long-term genetic experiment}

In 1960, a long-term experiment was set up at HREC to compare methods of genetic improvement in the performance of sheep for range conditions. The first experiment focused on the weaning (120-day) weights of lambs. Lines from a common base flock of grade Targhee sheep were set up in two locations. HREC represented a range environment, while the UC Davis campus flock was more typical of conditions in purebred flocks with better average nutrition
TABLE 1. Average 1992-1994 performance at HREC of lines selected for 120-day lamb weight (HW, DH), multiple births (HT) and an unselected control (HC)

\begin{tabular}{lrrrr}
\hline \hline & HW & DH & HT & HC \\
\cline { 2 - 5 } 120-day lamb weight $(\mathrm{kg})$ & 34.40 & 34.40 & 31.70 & 29.60 \\
No. lambs born/ewe lambing & 1.69 & 1.58 & 1.70 & 1.48 \\
Total 120-day lamb weight /ewe (kg) & 46.60 & 44.60 & 43.40 & 38.10
\end{tabular}

and less environmental stress. There were two lines at Davis, one (DW) selected for individual lamb 120-day weight (adjusted for age, type of birth and rearing, and age of dam), and an unselected control (DC). Corresponding lines ( $\mathrm{HW}$ and $\mathrm{HC}$ ) were developed at HREC. In addition, rams selected at Davis were used as sires each year at HREC for a third line (DH), to determine whether improvement made in a more favorable environment was expressed under range conditions. The HW-DH comparison can be thought of as contrasting the improvement made by two neighboring ranchers, one selecting his or her own rams and one buying them from a purebred flock kept under much better feed conditions. The experiment involved a total of 120 ewes per year in the Davis flock, and 300 to 400 ewes each year in the Hopland flock.

Increase in weaning weight. The increase in weaning weight achieved over the 17-year period that ended in 1977 was about 2.5 times greater at Davis (DW-DC) than at Hopland (HW-HC), a difference that was highly significant. Some of the improvement made at Davis was expressed under range conditions, but the $\mathrm{DH}-\mathrm{HC}$ difference was much less than the DW-DC difference, and about the same as the HW-HC difference (Lasslo et al. 1985a, 1985b). Ewe fertility and lamb survival declined slightly in HW compared to $\mathrm{HC}$, and significantly in line DH. This, combined with the weaning weight results, indicates that better performance in a range environment results from selection in that environment as opposed to selecting under more favorable conditions and "importing" the improved stock, in spite of the greater direct response in the better environment. Although the lack of replication of the lines limits the generalizability of these conclusions, the results strongly suggest that selection in the environment of use results in more productive animals.

It was not possible to continue the Davis lines after 17 years, but lines $\mathrm{HW}, \mathrm{DH}$ and $\mathrm{HC}$ were continued at HREC until 1994, with the DH rams selected within that line; that is, simi- 
lar to HW. Ewe fertility and lamb survival leveled off in both weightselected lines, and improved slightly in DH in the latest years, indicating improved adaptation with a period of selection in that environment. However, DH remained significantly lower than HW and HC in these measures of fitness (Bradford et al. 1999).

Multiple births. The long-term breeding project also involved selection for multiple births at HREC (Line HT) (Sakul et al. 1999). (Unfortunately, it was not possible to select for this trait at UC Davis.) The response per year for this trait, as for weaning weight, was less than predicted from published heritability estimates or reported from experiments conducted in nutritionally more favorable environments. Not surprisingly, the results suggest that inadequate nutrition limits the ability of animals to express their genetic potential for traits such as growth and prolificacy. However, this limitation does not preclude some selection response, and it does not rule out the conclusion that selection should be practiced in the environment of use.

Comparison of four lines. In spite of the rather slow rate of response for weaning weight and multiple births, results in the final years of the project indicate that significant improvement in economic traits can be made by selection, even in a limiting environment

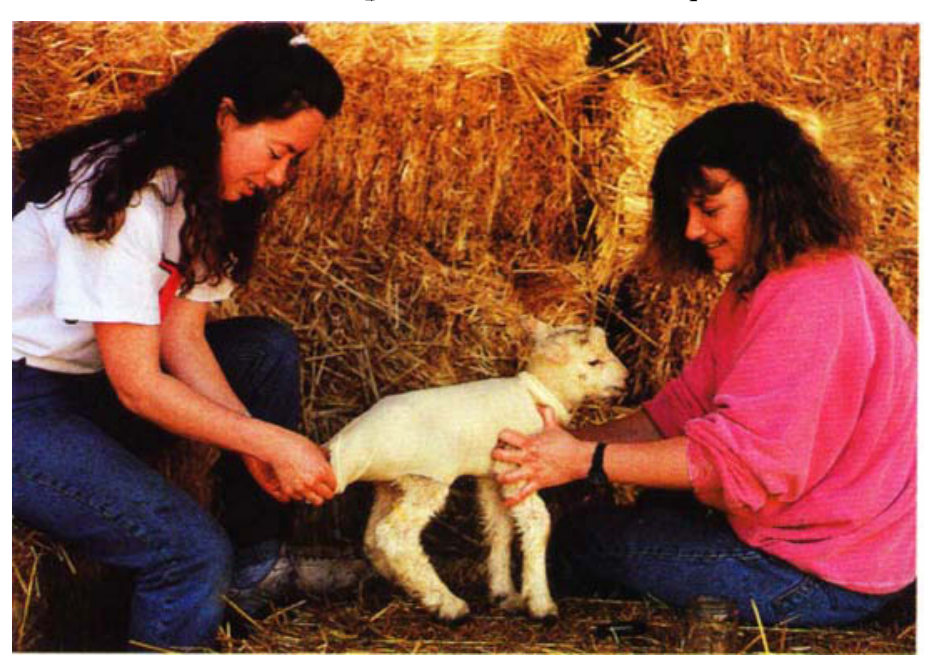

Meghan Gerzevske and Mary Kelly fit a stockinette jacket on a lamb before it is fostered to a ewe. Many undergraduate and graduate students have obtained research experience with sheep at HREC.

TABLE 2. Average daily gain (ADG), feed/gain $(\mathrm{kg})$ and carcass fat $(\%)$ of wether lambs from five sire groups*

\begin{tabular}{lcccc}
\hline \hline Sire group & No. & ADG $\mathbf{( k g )}$ & Feed /gain $\mathbf{( k g )}$ & Carcass fat (\%) \\
\hline HREC Targhee (HW, HT) & 25 & .31 & 6.2 & 24.0 \\
Texas Rambouillet & 23 & .27 & 6.6 & 24.8 \\
Dubois Rambouillet & 24 & .30 & 6.5 & 25.8 \\
Strong wool Merino & 24 & .28 & 6.2 & 26.8 \\
Fine wool Merino & 24 & .23 & 6.8 & 27.8 \\
\hline
\end{tabular}

- Source: Sakul, Dally et al. 1993

$\dagger$ Equal numbers of sires from weight-selected $(\mathrm{HW})$ and multiple birth-selected $(\mathrm{HT})$ lines.

(table 1). The selected lines were 14\% to $23 \%$ above the control in total weight of lamb per ewe. Ewes in the weight-selected lines were significantly heavier than the controls or HT, and would therefore be expected to require more feed. After adjustment for the estimated effect of ewe weight, the HW and HT lines produced an estimated $11 \%$ to $12 \%$ more lamb per unit of feed required, clearly an economically useful increase. Growth, feed conversion and carcass traits in progeny of HW and HT rams were compared with those from two highly selected strains each of U.S. Rambouillets and Australian Merinos (Sakul, Dally et al. 1993). The Hopland strains were equal to or better than each of the other groups in these traits, further supporting the conclusion that genetic improvement in performance occurred in the selected lines (table 2).

The effects of the selection for growth and litter size on component traits, including milk production, body composition, ovulation rate and prenatal survival, were also evaluated, providing new information on the biology of sheep production traits. The lines were discontinued following retirement of the project leader, but semen and embryos from them were frozen, and good viability following transfer of embryos frozen for up to 3 years was demonstrated (Sakul, Bradford et al. 1993). Embryos and semen from these lines represent the first sheep germ plasm stored in the National Animal Germplasm Program laboratory established by the U.S. Department of Agriculture in Ft. Collins, Colo.

More long-term research is needed on interactions between animal genotypes and the production environment, but funding and facilities for such projects are currently difficult to obtain. Also needed (and potentially more feasible) are comparisons of the productivity of different breeds and crosses, adapted to range conditions but differing in size and prolificacy, under alternative management strategies such as different lambing seasons and levels of supplementation. Future research should focus on additional assessments of inputs such as amount and cost of feed as well as outputs such as meat production per acre, and on the impact of production practices on range conditions and sustainability.

\section{Maternal behavior}

Most well nourished ewes produce enough milk to support two lambs. However, some ewes give birth to single lambs and some bear more than two. Therefore it makes sense for sheep breeders to entice ewes bearing single lambs to adopt one of these "extra" lambs, or possibly an orphan that has lost its mother. Fostering (grafting) lambs from one mother to another is not especially difficult if it is accomplished at the time of birth before the ewe has contacted her newborn. However, once she has groomed her young and formed a bond with it, a process that may take only minutes, it is extremely difficult to entice her to accept an alien lamb. She may butt the alien 


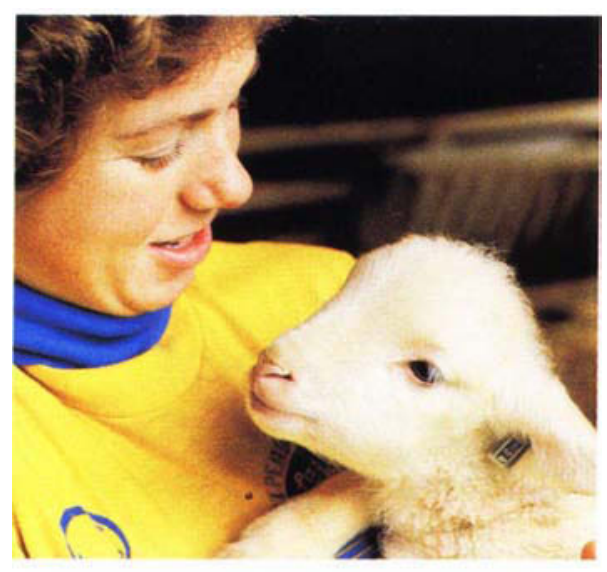

Scientists at Hopland have developed easy, inexpensive and effective methods for fostering lambs; sheep breeders have also benefited from simple behavioral tests to determine the sexual performance of rams. Former UC Davis student Jennifer Baldwin assisted in an odor-transfer/ substitution study.

lamb if it approaches or move away if it tries to suckle.

For hundreds of generations, domestic ewes and their wild ancestors have been naturally selected to care for only their own offspring and to actively reject alien young. In the late 1970 s, investigations were initiated at HREC to develop improved and costefficient fostering techniques. An initial study was designed to determine the efficacy of restraining ewes to facilitate adoptions (Price, Dunbar et al. 1984), since this technique was widely used in the industry. When restrained, the ewe can not avoid the suckling attempts of the alien lamb or exhibit aggression toward it. The study found that, on average, restrained ewes would accept an alien lamb substituted for their own lamb after 4 to 5 days of cohabitation with the alien lamb.

In another study, a tranquilizer was used to reduce the aggressive responses of the foster mother (Tomlinson et al. 1982). Although the tranquilizer was effective in inducing ewes to accept an alien lamb substituted for her own lamb (substitution mode), it did not increase the propensity of ewes to accept an alien lamb in addition to her own offspring (add-on mode).

Further study employed cloth stockinette jackets made of elastic, knitted fabric placed on the ewe's own live (or dead) lamb at birth (Price, Dunn et al. 1984). The stockinette jackets acquired the natural odor of the ewe's own lamb, and when the jacket was transferred to an alien in the substitution mode, the alien was accepted more than $85 \%$ of the time. In addition, about $40 \%$ of the ewes immediately accepted the alien lamb upon first introduction. This result was encouraging, considering that only an occasional ewe would accept an alien wearing a "clean" jacket (control treatment). It also confirmed the importance of olfactory cues in offspring discrimination.

A more important study for the sheep industry was then initiated on enticing ewes with a single lamb to accept a second alien lamb (add-on mode) (Martin et al. 1987). Separate jackets worn by the foster ewe's own lamb and an alien lamb were exchanged at the time of fostering (initial introduction of the alien lamb) so that her own lamb carried alien-lamb odor and, more importantly, the alien carried "own-lamb" odor. Under these circumstances, approximately $70 \%$ of the ewes adopted the alien lamb in addition to their own lamb but, as in the substitution experiments, only $40 \%$ of the ewes immediately accepted the alien.

While the stockinette research was being conducted, the investigators also examined the efficacy of using an artificial odorant to facilitate fostering (Price et al. 1998). Neatsfoot oil (a natural animal product often used to preserve leather) was smeared on the ewe's own lamb shortly after birth and the foster ewe was introduced to an alien lamb that had also been rubbed with neatsfoot oil. Only $50 \%$ of the ewes accepted the alien with this treatment. However, $80 \%$ of those adopting the alien did so immediately. Because of the high percentage of immediate adoptions, a subsequent experiment was performed, using both stockinettes and neatsfoot oil (Price et al. 1998). An additive effect was observed; $80 \%$ of the foster ewes accepted the alien as well as their own lamb and, of those ewes adopting aliens, $83 \%$ did so immediately.

In summary, HREC research on the maternal behavior of ewes identified new procedures that are superior to the traditional restraint technique for fostering alien lambs to ewes that have already bonded with their natural lambs. The 4-to-5-day acceptance period with restraint fostering is relatively lengthy. Most commercial sheep breeders have limited facilities to house individual ewes and lambs for an extended period. In addition, they have many other animals and chores to attend to during the lambing season. The more rapid and efficient odor-transfer technique for fostering lambs has been adopted by many sheep breeders in the United States and abroad. When coupled with the addition of a novel odorant, this technique can result in a high percentage of immediate adoptions. The odortransfer and novel-odorant procedures are relatively inexpensive and require little training to use effectively. Stockinette jackets are now being sold commercially for both fostering and keeping young lambs warm in colder climates.

A logical extension of the fostering research conducted at HREC is to determine the chemical compounds (that is, olfactory cues) used by ewes to differentiate their own from alien young. This information could be used to more efficiently match the odors of own and alien lambs. An alternative approach would be to develop costefficient techniques for artificially simulating the neurophysiological changes occurring in the ewe at the time she gives birth to "reopen the window" of maternal acceptance.

\section{Sexual behavior}

In the 1980s, work was initiated at HREC on the development and expression of sexual behavior in rams. Several investigators had reported that about $30 \%$ of rams maintained in an all-male group from weaning to 2 years of age would initially show no interest in estrous (sexually receptive) ewes. Investigations at HREC demonstrated that the initial disinterest of 


\section{Roberto D. Sainz}

In 1983, a sheep breeder in Oklahoma noticed a ram with exceptional muscling, especially in the hindquarters. This ram, Solid Gold, was mated to normal ewes, and the condition was passed on to their offspring. Eventually the extra muscling was found to be due to a spontaneous mutation, a natural change in the animal's genetic code. Because the muscle hypertrophy (enlargement) is most pronounced in the hindquarters, the condition was named callipyge, a Greek word meaning "beautiful buttocks." Needless to say, sheep breeders were immediately interested in the meat production potential of lambs carrying the callipyge gene.

Callipyge lamb carcasses clearly yield more meat than normal lambs, but this advantage is useless if the meat is of inferior quality. Specifically, there is concern that meat from callipyge lambs is tougher than normal. Meat tenderization results from the breakdown of muscle structure (myofibrils) after slaughter, a process mediated by naturally occurring muscle enzymes (calpains) and inhibited by a protein called calpastatin. The progress of this tenderization can be assessed in the laboratory by measuring the fragmentation of myofibrillar proteins using a spectrophotometer. The myofibrillar fragmentation index generally begins at 30 (at

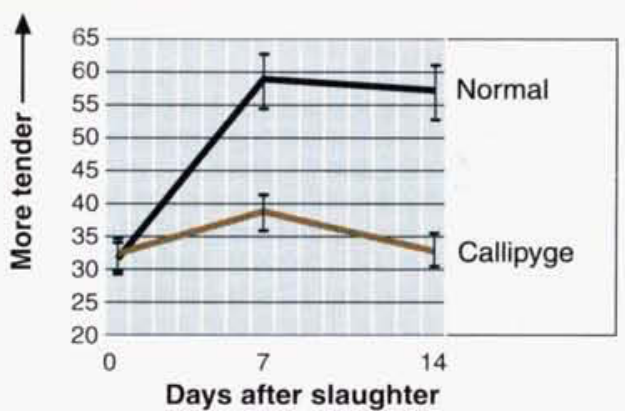

Fig. 1. Postmortem changes in myofibrillar fragmentation index ( $y$-axis) in longissimus muscles of normal and callipyge lambs. Muscles were stored at $31^{\circ} \mathrm{F}\left(-0.5^{\circ} \mathrm{C}\right)$ for 1,7 or 14 days postmortem. A higher myofibrillar fragmentation index indicates greater meat tenderness. slaughter), and must be greater than 50 for lamb to be considered tender.

A study was conducted at the UC Hopland Research and Extension Center (HREC) to compare the growth, carcass quality and meat quality of lambs born to HREC ewes but sired by either normal or callipyge rams using artificial insemination techniques. Six lambs of each genotype were raised with their dams until weaning and then transferred to UC Davis where they were fed until they reached market weight, and then harvested.

None of the preweaning or postweaning growth traits differed between genotypes. At slaughter, callipyge lamb carcasses had greater dressing percentages $(60.5 \%$ versus $57.4 \%)$ and yields of major cuts $(60.4$ pounds versus 53.4 pounds), and lower total carcass fat content $23.3 \%$ versus $28.5 \%$ ) as compared with normal lambs $(P<0.05)$. In addition, loin eye areas (4.1 square inches versus 2.8 square inches) and leg weights (25.1 pounds versus 21.4 pounds) were greater and backfats were lower $(0.17$ inches versus 0.27 inches) in callipyge lamb carcasses as compared with normal $(P<0.05)$.

Meat samples from normal lambs exhibited the expected patterns of postmortem myofibrillar fragmentation, resulting in tender meat by day 7 (fig. 1). By contrast, meat from callipyge lambs showed no fragmentation from day 1 to day 14 postmortem, resulting in tough meat. This was probably due to the higher activity of calpastatin in loin muscles from callipyge lambs as compared to normal lambs (6.6 units per gram versus 3.1 units per gram, $P<0.001)$.

In conclusion, lambs expressing the callipyge phenotype produce leaner, more muscular carcasses that yield more saleable quantities of meat than normal lambs. However, industry adoption of the callipyge genotype is limited by the increased toughness in some hypertrophied muscles, which seems to be related to high calpastatin activity and low myofibrillar fragmentation. Several technologies have been developed to overcome this problem, such as freezing and thawing (destroys calpastatin activity), calcium chloride injections and vitamin D feeding (increases calpain activity) and even hydrodynamic shock (physically disrupts the myofibril). So far, none of these techniques has been adopted by the packing industry because of high initial costs and uncertain benefits. Until this happens, the opportunities that the callipyge genotype offers will go unused.

R.D. Sainz is Associate Professor, Department of Animal Science, UC Davis. 


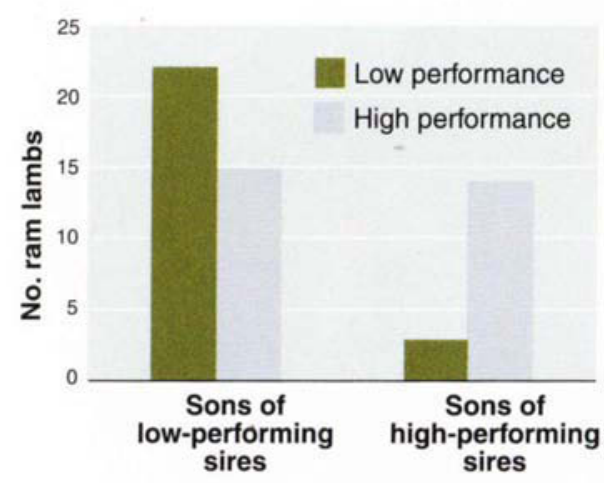

Fig. 1. Number of ram lambs exhibiting low and high levels of sexual performance sired by rams selected for low and high sexual performance. Low-performing ram lambs averaged 2.5 or fewer successful matings with sexually receptive ewes in 30-minute tests, compared with an average of $\mathbf{3 . 5}$ or more for high-performing rams.

yearling rams toward estrous ewes could be attributed to a lack of exposure to ewes during their first year of life (Price et al. 1994). Ram lambs given several hours of direct exposure to estrous ewes in the months following puberty almost always exhibited normal interest in females as yearlings. In addition, they exhibited higher levels of sexual performance (number of completed matings per unit time) than males denied early contact with ewes. An intermediate advantage was noted when ram lambs were given fenceline contact with ewes over a 3-week period during their first year (Price et al. 1999). In spite of these treatments, an occasional ram would develop a sexual preference for males and ignore females. Semen was collected from these maleoriented rams and used to inseminate ewes. The sons of the male-oriented rams were no more likely to be maleoriented than the sons of femaleoriented rams (unpublished data).

The sexual performance of individual rams can be highly variable. A standard serving capacity test was used at HREC to characterize the ability and desire of rams to mate with estrous ewes (Price et al. 1991). Males were individually exposed to four unrestrained estrous ewes in a small pen for 30 minutes and the number of completed matings (ejaculations) and mounts without ejaculation were recorded. An alternative but less accu- rate method for assessing the sexual performance of rams is to observe their behavior when housed in a pen adjacent to ewes. High-performing rams spend more time along the fenceline observing ewes than lowperforming rams (Price et al. 1999). High-performing rams were more efficient breeders in different ways. They not only attained more completed matings per unit time, they also switched females more frequently; that is, they mated with a greater number of different females (Price et al. 1996).

Although high-performing males were more aggressive toward one another than low-performing males when competing for females, they were not more aggressive when competing for feed (Erhard et al. 1998). Furthermore, sexual performance was inherited. High-performing rams were more likely to sire high-performing than low-performing sons, and the male offspring of low-performing rams ranked among the poorest breeders (Bench et al. 2001) (fig. 1). Interestingly, the daughters of highperforming rams exhibited their first behavioral estrus an average of 8 days earlier than the daughters of low-performing rams. No difference in ovulation rate at first estrus was found between these two groups of female progeny.

Most sheep breeders hesitate to use ram lambs in their first year of life as sires for their breeding flock because of a lack of physical development and a belief that ram lambs are less efficient breeders. HREC research has shown that the number of completed matings per unit time for ram lambs is slightly lower than for yearling rams (Price et al. 1991). In addition, older rams dominate ram lambs when housed together. It is also true that ewes are more attracted to larger, adult rams and rams that are more sexually active (Estep et al. 1989).

In spite of these disadvantages, it is clear that ram lambs can be effective flock sires if managed properly. These studies of ram sexual behavior provide alternative management tools to improve the efficiency of sheep breed- ing programs. Although many sheep breeders do not use rams as flock sires until their yearling year, most ram lambs are fully capable of impregnating ewes at acceptable levels if they are not mixed with more dominant adult rams. Ram lambs accelerate the progress made in artificial selection programs by shortening the generation interval. An additional bonus is that ram lambs given sexual experience in their first year of life become more efficient sires as adults.

Sheep breeders now have several relatively simple behavioral tests that can be used to determine the sexual performance of rams. Selecting highperforming rams as flock sires improves the reproductive efficiency of the next generation of males, and fewer males are needed to maximize the reproductive potential of the flock. Additional research is needed to determine how the sexual performance of male sheep can be predicted or modified early in life to allow sheep breeders to make wise decisions on their intended use as either meat animals or sires for their breeding flocks.

E.O. Price is Professor and G.E. Bradford is Professor Emeritus, Department of Animal Science, College of Agricultural and Environmental Sciences, UC Davis. The authors acknowledge the assistance of Martin R. Dally, Staff Research Associate, and Donald T. Torrell, former Animal Science Specialist, Department of Animal Science, HREC.

\section{References}

Bench CJ, Price EO, Dally MR, et al. 2001. Artificial selection of rams for sexual performance and its effect on the sexual behavior and fecundity of male and female progeny. Appl Anim Behav Sci 72:41-50.

Bradford GE, Sakul H, Dally MR. 1999. Selection for litter size or weaning weight in range sheep: II. Correlated responses and effect on productivity. Sheep Goat Res J 15:134-42.

Bradford GE, Torell DT, Spurlock GM, Weir WC. 1963. Performance and variability of offspring of crossbred and purebred rams. J Anim Sci 22:617-23.

Bradford GE, Weir WC, Torell DT. 1960. Growth rate, carcass grades and net returns of Suffolk- and Southdown-sired lambs under range conditions. J Anim Sci 19:493-501. 
Erhard HW, Price EO, Dally MR. 1998. Competitive ability of rams selected for high and low levels of sexual performance. Anim Sci 66:403-8.

Estep DQ, Price EO, Wallach SJ, et al. 1989. Social preferences of domestic ewes for rams (Ovis aries). Appl Anim Behav Sci 24:287-300.

Lasslo LL, Bradford GE. Torell DT, et al. 1985a. Selection for weaning weight in Targhee sheep in two environments. I. Direct response. J Anim Sci 61:376-86.

Lasslo LL, Bradford GE, Torell DT, et al. 1985b. Selection for weaning weight in Targhee sheep in two environments. II. Correlated effects. J Anim Sci 61:387-409.

Martin NL, Price EO, Wallach SJ, Dally MR. 1987. Fostering lambs by odor transfer: The add-on experiment. J Anim Sci 64:1378-83.

Price EO, Borgwardt R, Blackshaw JK, et al. 1994. Effect of early experience on the sexual performance of yearling rams. Appl Anim Behav Sci 42:41-8.

Price EO, Borgwardt R, Dally MR, et al. 1996. Repeated matings with individual ewes by rams differing in sexual performance. J Anim Sci

74:542-4.

Price EO, Borgwardt R. Dally MR. 1999. Effect of early fenceline exposure to estrous ewes on the sexual performance of yearling rams. Appl Anim Behav Sci 64:241-7.

Price EO, Dally MR,

Erhard HW, et al. 1998.

Manipulating odor cues

facilitates add-on fostering

in sheep. J Anim Sci

76:961-4

Price EO, Dunbar JM, Dally MR. 1984. Behavior of ewes and lambs subjected to restraint fostering. J Anim Sci 58:1084-9.

Price EO, Dunn GC, Talbot JA, et al. 1984. Fostering lambs by odor transfer: The substitution experiment. J Anim Sci 59:301-7.

Price EO. Estep DQ, Wallach SJ, et al. 1991. Sexual performance of rams as determined by maturation and sexual experience. J Anim Sci 69:1047-52.

Sakul H, Bradford GE, BonDurant RH, et al. 1993. Cryopreservation of embryos as a means of germ plasm conservation in sheep. Theriogenol 39:401-9.

Sakul H, Bradford GE, Dally MR. 1999. Selection for litter size or weaning weight in range sheep: I. Selection practiced and direct response. Sheep Goat Res J 15:122-33.

Sakul H, Dally MR, Bradford GE. 1993. Evaluation of Australian merino and U.S. sheep breeds for feed and carcass traits. $J$ Anim Sci 71:363-8.

Tomlinson KA, Price EO, Torell DT. 1982 Responses of tranquilized postpartum ewes to alien lambs. Appl Anim Ethol 8:109-17.

\section{Is there a sire-dam interaction in sperm fertilizing potential?}

Trish Berger a Martin R. Dally

TO optimize the efficiency of food animal production, a high level of reproductive efficiency is required because producers must spend a large proportion of their resources on the breeding herd. Previous research has demonstrated significant variation in the fertility of males. Our project was designed to evaluate whether there is a malefemale interaction in the fertilizing potential of sheep sperm.

The fertilizing potential of sperm is based on characteristics of the semen, or on the interaction of semen characteristics with those of the female reproductive tract, or both. To the extent that the fertilizing potential of sperm is based on the interaction with characteristics of the female reproductive tract, fertility is femaledependent (that is, there is a male-female interaction). These possibilities were tested by inseminating individual ewes with equal numbers of cryopreserved sperm from the same two rams in two consecutive breeding seasons.

Estrus was synchronized in five groups of approximately 30 Targhee-type white-faced ewes using progesterone-impregnated vaginal sponges. The ewes were inseminated with a mix of equal numbers of sperm from one of five different combinations of Merino and Suffolk rams. Ewes that lambed the first year were inseminated in the second year with the same combination of cryopreserved semen. The sire of each lamb was determined based on the coat color of the offspring's head and legs. The percentage of lambs sired by each male was determined for each semen combination using all lambs born to obtain an evaluation of the fertilizing potential of the two sources of sperm in each combination. Some ewes produced lambs sired only by the more fertile ram, and some gave birth to offspring sired only by the less fertile ram, or both. Ewes were divided into subgroups based on the sire or sires of lambs born the first year. The proportion of lambs sired by each male for these same ewes in the second breeding season was examined in the subgroups.

A total of 45 to 70 lambs (from 18 to 22 ewes) was born to each of the five combinations of sire semen. The more fertile semen in the combination produced $73 \%$ to $82 \%$ of the offspring. Twelve to 15 ewes in each of the five groups lambed twice to their respective semen combination. With a sireewe interaction, ewes conceiving to the more fertile semen the first year would be more likely (than the flock average) to conceive to that same semen the second year. Similarly, ewes conceiving to the less fertile semen the first year would be more likely to conceive to that same semen the second year. However, when ratios of lambs born the second year in the various subgroups were compared with ratios of lambs born the first year in those same subgroups, five of the 10 subgroups varied significantly $(P<0.01$ to $P<0.001)$. The lack of a sire-ewe interaction in this study suggests that the factors influencing the fertilizing potential of sperm are specific to the sperm rather than to the interaction with the female reproductive tract.

T. Berger is Professor, Department of Animal Science, UC Davis; and M.R. Dally is Staff Research Associate, Department of Animal Science, HREC. 